\title{
PENERAPAN MODEL PEMBELAJARAN CORE UNTUK MENINGKATKAN PRESTASI BELAJAR PESERTA DIDIK PADA POKOK BAHASAN KESETIMBANGAN ION DAN pH LARUTAN GARAM
}

\author{
Nesa Nozari, Herdini, Asmadi M. Noer *
}

Program Studi Pendidikan Kimia, Fakultas Keguruan dan Ilmu Pendidikan Universitas Riau, Kampus Binawidya KM 12,5, Pekanbaru 28293, Riau, Indonesia.

\begin{tabular}{l}
\hline \multicolumn{1}{c}{ Informasi Artikel } \\
\hline Sejarah Artikel: \\
Diterima: $20-06-2019$ \\
Disetujui : 30-01-2020 \\
Dipublikasikan: 31-01-2020 \\
\hline Keywords: \\
CORE learning model, \\
chemistry learning, \\
learning achievement, \\
equilibrium of ion and $p H$. \\
\hline
\end{tabular}

\begin{abstract}
A b s trak
Penelitian ini bertujuan untuk meningkatkan prestasi belajar peserta didik pada pokok bahasan kesetimbangan ion dan $\mathrm{pH}$ larutan garam di kelas XI IPA SMAN 6 Pekanbaru. Jenis penelitian ini adalah penelitian eksperimen dengan desain pretest-posttest. Pemilihan sampel dilakukan dengan uji homogenitas sehingga didapat sampel dari penelitian adalah peserta didik kelas XI IPA 2 sebagai kelas eksperimen dan peserta didik pada kelas XI IPA 1 sebagai kelas kontrol. Kelas eksperimen diterapkan model pembelajaran CORE (connecting, organizing, reflecting and extending), sedangkan kelas kontrol diberikan pembelajaran tanpa CORE. Teknik analisis data yang digunakan adalah uji-t. Berdasarkan hasil uji analisis data diperoleh thitung $>$ tabel yaitu 9,03 > 1,66 dengan $\mathrm{n}$-gain 0,72 yang termasuk kategori peningkatan tinggi, artinya penerapan model pembelajaran CORE dapat meningkatkan prestasi belajar peserta didik pada pokok bahasan kesetimbangan ion dan $\mathrm{pH}$ larutan garam di kelas XI IPA SMA Negeri 6 Pekanbaru.
\end{abstract}

\begin{abstract}
A b s tract
The research aims to improve student learning results on ion equilibrium and $\mathrm{pH}$ of salt solution in class XI IPA SMAN 6 Pekanbaru. This is an experimental study with a pretest-posttest design. The sample study was students of class XI IPA 2 as an experimental class and students in class XI IPA 1 as a control class. The experimental class is the class applied to the CORE learning model while the control class is not treated. The data analysis technique used is the t-test. Based on the results of the data analysis test, tcount $>$ ttable is 9,03> 1.66, meaning that the application of CORE's learning model can improve student learning achievement on the subject of ion equilibrium and $\mathrm{pH}$ of salt solution in class XI IPA 6 SMAN 6 Pekanbaru.
\end{abstract}

\footnotetext{
*Alamat korespondensi:

e-mail: amnoer2007@yahoo.com

No. Telf: +628127676025
} 


\section{PENDAHULUAN}

Pembelajaran memiliki peranan penting untuk meningkatkan kompetensi yang dimiliki peserta didik. Keberhasilan proses belajar mengajar dapat dilihat dari pencapaian tujuan pembelajaran. Keberhasilan pencapaian tujuan pembelajaran tidak terlepas dari peran guru. Guru sebagai fasilitator, motivator dan pembimbing peserta didik dalam meningkatkan kemampuan peserta didik untuk memahami materi mengharuskan guru memiliki strategi, metode, media dan model yang tepat, sehingga proses pembelajaran dapat berlangsung efektif. Model pembelajaran yaitu suatu perencanaan atau suatu bentuk yang digunakan sebagai pedoman dalam melaksanakan pembelajaran dikelas (Trianto, 2015). Joyce and Weil (dalam Trianto, 2015) menyatakan bahwa model pembelajaran merupakan model belajar, dengan model belajar tersebut guru dapat membantu peserta didik dalam mendapatkan ide, informasi, keterampilan, cara berpikir dan mengekspresikan diri mereka sendiri. Model pembelajaran sangat mempengaruhi suasana belajar peserta didik sehingga dapat berpengaruh pada prestasi belajar peserta didik. Pemilihan model pembelajaran disesuaikan dengan mata pelajaran agar menarik dan memotivasi peserta didik terhadap materi pelajaran, termasuk dalam mata pelajaran kimia.

Kesetimbangan ion dan $\mathrm{pH}$ larutan garam merupakan salah satu materi yang diajarkan pada mata pelajaran kimia di kelas XI IPA SMA. Hasil wawancara yang telah dilakukan dengan salah seorang guru kimia SMA Negeri 6 Pekanbaru bahwa nilai rata-rata ulangan peserta didik kelas XI tahun ajaran 2017/2018 pada pokok bahasan kesetimbangan ion dan $\mathrm{pH}$ larutan masih tergolong rendah. Hal ini terlihat dari persentasi ketuntasan peserta didik hanya sebesar 42,6\%, sehingga 57,4\% lainnya masih di bawah KKM (Kriteria Ketuntasan Minimum). KKM yang telah ditetapkan sekolah yaitu 75 . Hal ini disebabkan karena pembelajaran yang ada kurang didominasi peserta didik, dimana peserta didik hanya mendengarkan penjelasan dari guru saja sehingga kurangnya aktivitas dan keterlibatan peserta didik dalam proses pembelajaran, usaha lain juga sudah dilakukan yaitu dengan menerapkan metode diskusi namun hanya beberapa peserta didik yang tertarik dan ikut berdiskusi. Peserta didik masih canggung atau kaku dalam diskusi yang telah diterapkan oleh guru dan peserta didik masih banyak yang pasif sehingga menyebabkan materi pelajaran tidak dapat dipahami secara utuh dan berdampak pada prestasi belajar peserta didik yang dibawah KKM.

Mengatasi masalah di atas, guru dituntut agar mampu memilih dan menerapkan model pembelajaran yang dapat merangsang peserta didik lebih aktif berpartisipasi dalam pembelajaran supaya dapat mengurangi kebosanan dan menumbuhkan minat peserta didik, sehingga dapat meningkatkan prestasi belajarnya. Salah satu alternatif model pembelajaran yang diharapkan dapat menyelesaikan permasalahan tersebut adalah dengan menerapkan model pembelajaran CORE.

Model pembelajaran CORE dikembangkan oleh Robert C. Calfee pada tahun 2004, model ini menganut teori konstruktivisme, peserta didik membangun, menghubungkan atau mengaitkan informasi pada pengetahuannya berupa konsep atau lainnya yang telah dimilikinya (Ratna Wilis Dahar, 2011). Menurut Wahyudi Siswanto dan Dewi Ariani (2016) model pembelajaran CORE yaitu model yang mencakup empat aspek kegiatan yaitu Connecting, Organizing, Reflecting dan Extending.

Tahap connecting, merupakan kegiatan menghubungkan informasi lama dengan informasi baru atau antar konsep, organizing merupakan kegiatan mengorganisasikan informasi-informasi yang diperoleh untuk memahami materi yang diajarkan, reflecting adalah cara berfikir kebelakang tentang apa yang sudah dilakukan dalam hal belajar dimasa lalu. Suyatno (2009) mengatakan bahwa reflecting merupakan kegiatan memikirkan kembali informasi yang sudah didapat dan kemudian extending merupakan tahap dimana peserta didik dapat memperluas pengetahuan mereka tentang apa yang sudah diperoleh selama proses pembelajaran berlangsung.

Penelitian ini bertujuan untuk implementasikan pembelajaran CORE untuk meningkatkan prestasi belajar peserta didik. Model pembelajaran CORE ini diterapkan pada materi kesetimbangan 
ion dan $\mathrm{pH}$ larutan garam dan dijalankan pada Sekolah Menengah Atas (SMA) Negeri 6 Pekanbaru, Riau.

\section{METODE PENELITIAN}

Bentuk Penelitian adalah penelitian eksperimen dengan design pretest-posttest. Desain penelitian yang digunakan yaitu Design Randomized Kontrol Group Pretest-Posttest. Penelitian dilaksanakan pada semester genap tahun ajaran 2018/2019 yaitu bulan Januari-Mei 2019. Populasi dalam penelitian adalah seluruh peserta didik kelas XI IPA SMA Negeri 6 Pekanbaru yang terdiri dari 6 kelas. Sampel diambil berdasarkan hasil analisis uji normalitas dan uji homogenitas tes nilai ulangan asam basa. Dari uji normalitas dan uji homogenitas diketahui bahwa kelas XI IPA 1 dan XI IPA 2 berdistribusi normal dan mempunyai kemampuan yang sama (homogen), maka kedua kelas tersebut dijadikan sebagai sampel. Diperoleh Kelas XI IPA 2 sebagai kelas eksperimen dan kelas XI IPA 1 sebagai kelas kontrol.

Tabel 1. Rancangan Penelitian (Sugiyono, 2017)

\begin{tabular}{cccc}
\hline Kelas & Pretest & Perlakuan & Posttest \\
\hline Eksperimen & $\mathrm{T}_{0}$ & $\mathrm{X}$ & $\mathrm{T}_{1}$ \\
Kontrol & $\mathrm{T}_{0}$ & - & $\mathrm{T}_{1}$ \\
\hline
\end{tabular}

Teknik pengumpulan data dalam penelitian adalah teknik test prestasi belajar. Data yang dikumpulkan diperoleh dari: (1). Data hasil nilai test soal ulangan asam basa sebagai data awal yang digunakan untuk uji homogenitas. (2). Nilai pretest dan posttest pada kelas eksperimen dan kelas kontrol (pokok bahasan kesetimbangan ion dan $\mathrm{pH}$ larutan garam) yang digunakan untuk uji hipotesis. Sedangkan teknik analisis data yang digunakan pada penelitian adalah uji-t. pengujian statistik dengan uji-t dapat dilakukan berdasarkan kriteria data yang berdistribusi normal. Oleh sebab itu, sebelum dilakukan pengolahan data, terlebih dahulu dilakukan uji normalitas menggunakan uji Liliefors. Jika harga $L_{\text {maks }}<$ Ltabel, maka data berdistribusi normal. Harga Ltabel diperoleh dengan rumusan (1) (Irianto, 2003):

$$
L=\frac{0,886}{\sqrt{n}}
$$

Setelah data berdistribusi normal, kemudian dilakukan uji homogenitas dengan menguji varians kedua sampel (homogen atau tidak) terlebih dahulu dengan persamaan (2):

$$
\mathrm{F}=\frac{\text { Varians Terbesar }}{\text { Varians Terkecil }}
$$

Kemudian dilanjutkan dengan uji kesamaan rata-rata menggunakan uji-t dua pihak untuk mengetahui kehomogenan kemampuan kedua sampel. Uji hipotesis yang digunakan merupakan uji-t pihak kanan dengan rumusan (3):

$$
\mathrm{t}=\frac{\overline{x_{1}}-\bar{x}_{2}}{S_{g} \sqrt{\frac{1}{n_{1}}+\frac{1}{n_{2}}}}
$$

Dengan Sg merupakan standar deviasi gabungan yang dapat dihitung menggunakan rumus (4):

$$
S_{g}=\frac{\frac{\left(n_{1}-1\right) S_{1}^{2}+\left(n_{2}-1\right) S_{2}^{2}}{n_{1}+n_{2}-2}}{2}
$$

(Sudjana, 2005) 
Untuk menunjukkan kategori peningkatan prestasi belajar peserta didik dengan penerapan model pembelajaran Osborn dilakukan uji gain ternormalisasi ( $N$ - Gain) dengan rumus (5)

$$
\mathrm{g}=\frac{\text { skor postest-skor pretest }}{\text { Skormaksimum-skor pretest }}
$$

Untuk melihat kategori nilai N - Gain ternomalisasi dapat dilihat pada Tabel 2.

Tabel 2. Nilai N - Gain ternormalisasi dan kategori (Hake, 1998)

\begin{tabular}{cc}
\hline Rata-rata $N$-Gain ternormalisasi & Kategori \\
\hline$N$-Gain $\geq 0,70$ & Tinggi \\
$0,30 \leq N$-Gain $<0,70$ & Sedang \\
$N$-Gain $<0,30$ & Rendah \\
\hline
\end{tabular}

\section{HASIL DAN PEMBAHASAN}

\section{Hasil Analisis Data}

Hasil uji normalitas yang dilakukan pada data awal, data pretest dan data postest dapat dilihat pada Tabel 2

Tabel 2. Hasil Uji Normalitas

\begin{tabular}{llllllll}
\hline Data & Kelas & $\mathbf{N}$ & $\overline{\mathbf{X}}$ & $\mathbf{S}$ & L maks & L tabel & Keterangan \\
\hline \multirow{6}{*}{ Awal } & XI IPA 1 & 34 & 58,35 & 14,20 & 0,10 & 0,15 & Berdistribusi Normal \\
& XI IPA 2 & 35 & 54,05 & 14,79 & 0,12 & 0,15 & $\begin{array}{l}\text { Berdistribusi Normal } \\
\text { Tidak Berdistribusi }\end{array}$ \\
& XI IPA 3 & 35 & 58,62 & 11,88 & 0,19 & 0,15 & $\begin{array}{l}\text { Normal } \\
\end{array}$ \\
& XI IPA 4 & 32 & 50,90 & 11,50 & 0,19 & 0,16 & Tidak Berdistribusi \\
& XI IPA 5 & 33 & 41,21 & 10,98 & 0,12 & 0,15 & Bermal \\
& XI IPA 6 & 33 & 57,69 & 13,89 & 0,10 & 0,15 & Berdistribusi Normal \\
\multirow{2}{*}{ Pretest } & XI IPA 1 & 34 & 25,41 & 6,60 & 0,11 & 0,15 & Berdistribusi Normal \\
\hline \multirow{2}{*}{ Posttest } & XI IPA 2 & 35 & 24,57 & 7,83 & 0,10 & 0,15 & Berdistribusi Normal \\
\hline & XI IPA 1 & 34 & 75,52 & 6,36 & 0,12 & 0,15 & Berdistribusi Normal \\
& XI IPA 2 & 35 & 81,25 & 8,22 & 0,10 & 0,15 & Berdistribusi Normal \\
\hline
\end{tabular}

\section{Uji Homogenitas}

Uji homogenitas dilakukan untuk mengetahui kelas (sampel) yang homogen agar nantinya bisa dipilih dua kelas sebagai kelas kontrol dan kelas eksperimen. Hasil analisis uji homogenitas dapat dilihat pada Tabel 3. 
Tabel 3. Hasil Pengolahan Data Uji Homogenitas

\begin{tabular}{|c|c|c|c|c|c|c|c|c|}
\hline Kelas & $\mathbf{N}$ & $\sum \mathbf{X}$ & $\overline{\mathbf{X}}$ & Ftabel & Fhitung & ttabel & thitung & Keterangan \\
\hline XI IPA 1 dan & 34 & 1984 & 58,35 & \multirow{2}{*}{1,80} & \multirow{2}{*}{1,08} & \multirow{2}{*}{1,67} & \multirow{2}{*}{1,23} & \multirow{2}{*}{ Homogen } \\
\hline XI IPA 2 & 35 & 1892 & 54,05 & & & & & \\
\hline XI IPA 1 dan & 34 & 1984 & 58,35 & \multirow{2}{*}{1,82} & \multirow{2}{*}{1,67} & \multirow{2}{*}{1,67} & \multirow{2}{*}{5,51} & Tidak \\
\hline XI IPA 5 & 33 & 1360 & 41,21 & & & & & Homogen \\
\hline XI IPA 1 dan & 34 & 1984 & 58,35 & \multirow{2}{*}{1,82} & \multirow{2}{*}{1,05} & \multirow{2}{*}{1,67} & \multirow{2}{*}{0,19} & \multirow{2}{*}{ Homogen } \\
\hline XI IPA 6 & 33 & 1904 & 57,69 & & & & & \\
\hline XI IPA 2 dan & 35 & 1892 & 54,05 & \multirow{2}{*}{1,82} & \multirow{2}{*}{1,13} & \multirow{2}{*}{1,67} & \multirow{2}{*}{1,04} & \multirow{2}{*}{ Homogen } \\
\hline XI IPA 6 & 33 & 1904 & 57,69 & & & & & \\
\hline XI IPA 5 dan & 33 & 1360 & 41,21 & \multirow{2}{*}{1,82} & \multirow{2}{*}{1,60} & \multirow{2}{*}{1,67} & \multirow{2}{*}{5,35} & Tidak \\
\hline XI IPA 6 & 33 & 1904 & 57,69 & & & & & Homogen \\
\hline
\end{tabular}

Data pada Tabel 3 dapat dilihat ada tiga pasang kelas yang memiliki kemampuan yang sama atau homogen yaitu kelas XI IPA 1 dengan XI IPA 2, kelas XI IPA 1 dengan XI IPA 6 dan kelas XI IPA 2 dengan XI IPA 6, kemudian dipilih satu pasangan kelas yang homogen secara acak dan diperoleh kelas XI IPA 2 sebagai kelas eksperimen dan kelas XI IPA 1 sebagai kelas kontrol.

\section{Uji Hipotesis}

Data yang digunakan untuk uji hipotesis adalah selisih antara nilai pretest dan posttest yang menunjukkan besarnya peningkatan prestasi peserta didik sebelum dan sesudah belajar pokok bahasan kesetimbangan ion dan $\mathrm{pH}$ larutan garam dengan dan tanpa penerapan model pembelajaran CORE. Hasil analisis uji hipotesis dapat dilihat pada Tabel 4.

Tabel 4. Hasil Uji Hipotesis

\begin{tabular}{lllrllll}
\hline Kelas & $\mathbf{N}$ & $\sum \mathbf{X}$ & $\overline{\mathbf{X}}$ & Sgab & ttabel & thitung & Keterangan \\
\hline Ekperimen & 35 & 1984 & 56,70 & \multirow{2}{*}{3,03} & \multirow{2}{*}{1,68} & \multirow{2}{*}{9,03} & Hipotesis diterima \\
Kontrol & 34 & 1704 & 50,12 & & & & \\
\hline
\end{tabular}

Tabel 5. Kategori Peningkatan Prestasi Belajar Peserta Didik

\begin{tabular}{llllll}
\hline Kelas & $\mathrm{N}$ & Pretest $(\mathrm{Xi})$ & Posttest $(\mathrm{Xi})$ & N-gain & Kategori \\
\hline Eksperimen & 35 & 24,57 & 81,26 & 0,72 & Tinggi \\
Kontrol & 34 & 25,41 & 75,53 & 0,67 & Sedang \\
\hline
\end{tabular}

\section{PEMBAHASAN}

Peningkatan prestasi belajar peserta didik pada pokok bahasan kesetimbangan ion dan $\mathrm{pH}$ larutan garam menggunakan model pembelajaran CORE terjadi karena model pembelajaran CORE ini mampu membuat peserta didik terlibat secara aktif dalam proses pembelajaran. Setiap tahap model pembelajaran CORE yaitu connecting, organizing, reflecting dan extending sangat berperan penting dalam peningkatan prestasi belajar peserta didik karena dari awal sampai akhir pembelajaran peserta didik diajak untuk ikut berpartisipasi aktif sehingga dapat melatih daya ingat peserta didik dan memberikan pembelajaran lebih bermakna.

Aktifitas peserta didik yang dapat meningkatkan prestasi belajar peserta didik dalam proses pembelajaran dapat dilihat dalam setiap tahap pada model pembelajaran CORE. Tahap pertama yaitu tahap connecting yang merupakan tahap guru mengkoneksikan pengetahuan awal yang dimiliki peserta didik dengan membimbing jalan pikiran peserta didik untuk menghubungkan informasi lama dengan informasi baru. Pada tahap ini guru menghubungkan pengetahuan awal siswa dengan 
pengetahuan yang akan dipelajari melalui beberapa cara, salah satunya adalah dengan memberikan pertanyaan yang berhubungan dengan pokok bahasan sebelumnya kemudian mengaitkan dengan pokok bahasan yang akan dipelajari sehingga dapat membangun pengetahuan awal peserta didik. Sebuah konsep dapat dihubungkan dengan konsep lain dalam sebuah pembelajaran, dimana konsep yang akan diajarkan dihubungkan dengan konsep yang telah dimiliki oleh peserta didik. Tahapan connecting ini juga menjadi penting karena pada tahapan ini berkaitan dengan pengetahuan awal peserta didik yang berpengaruh langsung dengan kemampuan peserta didik dalam menerima materi yang baru, hal ini sesuai dengan pendapat Trianto (2014) yang menyatakan jika kemampuan awal yang dimiliki oleh seseorang tinggi maka akan mudah menerima materi baru yang akan pelajari.

Tahap kedua yaitu tahap organizing merupakan kegiatan peserta didik untuk dapat mengorganisasikan pengetahuan yang diperoleh, dalam membantu peserta didik untuk dapat mengorganisasikan pengetahuan berupa konsep, guru memfasilitasi peserta didik dengan memberikan lembar organizing yang dikerjakan secara individu. Hal ini bertujuan supaya semua peserta didik terlibat dalam membangun pengetahuan awalnya. Lembar organizing berisi pertanyaan-pertanyaan yang bertujuan agar peserta didik dapat menemukan dan dapat mengorganisasikan konsep atau informasi baru dengan baik. Peserta didik diminta untuk mengerjakan lembar organizing secara individu, dengan cara ini konsep yang didapat akan melekat lama diingatan peserta didik. Hal ini dikarenakan pertanyaan-pertanyaan yang ada didalam lembar organizing saling berkaitan sehingga dengan menjawab lembar organizing peserta didik lebih dapat mengorganisasikan konsep yang didapat dalam proses pembelajaran.

Pertanyaan yang berkaitan seperti di atas sangat membantu peserta didik dalam memahami dan mengorganisasikan konsep dalam proses pembelajaran. Hal ini sesuai dengan Andi Prastowo (2013) yang mengatakan bahwa model CORE termasuk model pembelajaran yang berlandaskan pada teori konstruktivisme dimana peserta didik harus dapat mengkonstruksikan pengetahuannya sendiri melalui interaksi diri dengan objek, fenomena, pengalaman dan lingkungannya sehingga, proses pembelajaran menjadi lebih bermakna dan dapat mempengaruhi perkembangan pengetahuan serta kemampuan berfikir pesera didik.

Tahap ketiga yaitu tahap reflecting, pada tahap reflecting peserta didik diminta untuk merefleksi jawaban lembar organizing dengan mengisi lembar reflecting didalam kelompok sesuai dengan perintah yang terdapat didalam lembar reflecting, didalam kelompok peserta didik melakukan diskusi mengenai jawaban lembar organizing mereka. Dalam diskusi ini, salah seorang anggota kelompok mempresentasikan jawaban lembar organizing-nya, sementara anggota kelompok yang lain menyimak, kemudian jika ada jawaban yang berbeda peserta didik diminta untuk berdiskusi dan dapat menyimpulkan jawaban yang benar seperti terlampir pada lampiran halaman. Pada dasarnya peserta didik dituntut untuk mampu mengumpulkan data berupa konsep pembelajaran yang benar. Hal ini bertujuan agar setiap kelompok mempunyai konsep, informasi serta teori yang akan berguna dalam menjawab LKPD. Hasil dari diskusi ditulis dalam lembar reflecting yang telah disediakan oleh guru. Proses diskusi seperti ini dapat membuat peserta didik lebih aktif dalam menanggapi atau bertanya jika tidak mengerti dengan konsep yang sedang dipelajari, melatih rasa tanggung jawab dan toleransi dalam menghargai pendapat sesama teman kelompok.

Kegiatan diskusi kelompok dilanjutkan dengan mengerjakan LKPD pada tahap extending. Tahap extending ini memberikan kesempatan kepada peserta didik untuk mensintesis pengetahuan mereka dan mengaplikasikan pengetahuan tersebut dalam suasana baru yaitu dengan mengerjakan LKPD sehingga dapat melatih kemampuan berpikir peserta didik. Bukan hanya pengerjaan LKPD, pada tahap extending ini guru kembali mengajak peserta didik untuk memikirkan kembali fenomena kehidupan sehari-hari pada saat awal pembelajaran dan bersama guru memulai hal tersebut sehingga pembelajaran peserta didik menjadi lebih bermakna dan dapat bertahan lama diingatan peserta didik.

Pemahaman peserta didik terhadap pokok bahasan kesetimbangan ion dan $\mathrm{pH}$ larutan garam pada setiap pertemuan dapat dilihat dari nilai evaluasi dan nilai LKPD. Rata-rata nilai LKPD dan nilai 
evaluasi peserta didik di kelas eksperimen sebesar 91,02 lebih tinggi dari pada nilai LKPD dan nilai evaluasi peserta didik di kelas kontrol 83,53). Aktifitas peserta didik juga dapat dilihat pada saat mempresentasikan hasil diskusinya didepan kelas. Keaktifan peserta didik kelas eksperimen lebih tinggi dibanding kelas kontrol dikarenakan peserta didik lebih percaya diri dengan jawaban LKPD mereka, karena telah mempunyai data yang didapat dari tahap organizing dan reflecting. Hal ini sesuai dengan pendapat Saifuddin Azwar (2005), bahwa individu dengan sikapnya akan berusaha memaksimalkan hal-hal yang diinginkannya. Dalam kaitannya dengan ini, peserta didik memiliki keinginan untuk mampu menjawab setiap pertanyaan dalam lembar organizing yang diberikan ketika berada pada tahap organizing karena peserta didik akan mempresentasikan jawaban tersebut didalam kelompok pada tahap reflecting secara bergantian setiap pertemuan yang telah ditentukan sebelumnya, sehingga peserta didik akan mengusahakan secara optimal dengan belajar agar dapat menjawab lembar organizing dan mempresentasikan dengan benar didalam kelompok masing-masing.

Kendala yang dihadapi pada saat penelitian yaitu pada pertemuan pertama peserta didik cenderung mencontek jawaban teman lain pada saat mengisi lembar organizing yang mana seharusnya dikerjakan individu. Namun setelah diingatkan dan dijelaskan kembali, pertemuan berikutnya peserta didik sudah mulai terbiasa dan mengikuti proses pembelajaran dengan baik.

\section{KESIMPULAN}

\section{A. Kesimpulan}

Berdasarkan hasil penelitian dan pembahasan dapat disimpulkan bahwa:

1. Penerapan model pembelajaran CORE (Connecting, Organizing, Reflecting and Extending) dapat meningkatkan prestasi belajar peserta didik pada pokok bahasan kesetimbangan ion dan $\mathrm{pH}$ larutan garam di kelas XI SMAN 6 Pekanbaru.

2. Peningkatan prestasi belajar peserta didik pada pokok bahasan kesetimbangan ion dan $\mathrm{pH}$ larutan garam di kelas XI IPA SMAN 6 Pekanbaru melalui model pembelajaran CORE berada pada kategori tinggi dengan $\mathrm{N}$-gain sebesar 0,72 .

\section{B. Rekomendasi}

Berdasarkan kesimpulan yang diperoleh, peneliti merekomendasikan kepada guru bidang studi kimia dapat menjadikan model pembelajaran CORE sebagai salah satu alternatif model pembelajaran untuk meningkatkan prestasi belajar peserta didik khususnya pada pokok bahasan kesetimbangan ion dan $\mathrm{pH}$ larutan garam.

\section{DAFTAR PUSTAKA}

Agus Irianto. 2003. Statistika Konsep Dasar dan Aplikasi. Kencana. Jakarta.

Dimyati dan Mudjiono. 2002. Belajar dan Pembelajaran. Rineka Cipta. Jakarta

Kemendikbud. 2016. Bahan Pelatihan Kurikulum 2013 tahun 2016. Kemendikbud. Jakarta

Saifuddin Azwar. 2005. Sifat Manusia : Teori dan Pengukurannya. Pustaka Belajar. Yogyakarta.

Sudjana. 2005. Metode Statistik. Tersito. Bandung.

Sugiyono. 2017. Metode Penelitian Kombinasi (Mix Methods). Alfabeta. Bandung.

Suharsimi Arikunto. 2013. Dasar-dasar Evaluasi Pendidikan. Bumi Aksara. Jakarta.

Ratna Wilis Dahar. 2011. Teori Belajar dan Pembelajaran. Erlangga. Jakarta.

Trianto. 2014. Model Pembelajaran Terpadu. Bumi Aksara. Jakarta.

Wahyudi Siswanto dan Dewi Ariani. 2016. Model Pembelajaran Menulis Cerita. Refika Aditama. Bandung. 